\title{
La función social de la propiedad en la jurisprudencia del Tribunal Constitucional chileno
}

The social function of property in the jurisprudence of the Chilean Constitutional Court

\section{Ximena Peralta Fierro (iD}

Licenciadas en Ciencias Jurídicas y Sociales, Chile

\section{Isabel Yáñez Morales (iD}

Licenciada en Ciencias Jurídicas y Sociales, Chile

\begin{abstract}
RESUMEN El propósito de este trabajo es el estudio y sistematización de la jurisprudencia del Tribunal Constitucional chileno relativa a la función social de la propiedad. Comenzaremos con la revisión de los conceptos de expropiación, limitación y expropiación regulatoria. Enseguida, veremos que la Constitución no define la función social de la propiedad, pero que esta es inherente a ella. Elaboraremos un concepto de función social, para luego referirnos a las limitaciones a la propiedad que se derivan de ella. Luego, veremos los criterios que determinan si una limitación a la propiedad es o no legítima. Por último, trazaremos algunas conclusiones finales.
\end{abstract}

PALABRAS CLAVE Función social de la propiedad, limitaciones a la propiedad, jurisprudencia constitucional.

ABSTRACT This work's purpose is the study and systematization of the Chilean Constitutional Court's jurisprudence regarding the social function of property. We will start by differentiating the institution of expropriation from those of limitation and regulatory expropriation. Subsequently, we'll clear that the Constitution has not defined the meaning of «social function» and that it applies to every type of property. We will then offer a concept of social function, and later refer to the limitations of property that derive from it. We will then sweep by the criteria which resolve whether a limitation is legitimate. Finally, we will draw final conclusions.

KEYWORDS Social function of property, limitations, constitutional jurisprudence. 


\section{Introducción}

\section{Propósito de este trabajo'}

Este artículo tiene por propósito el estudio y sistematización de la jurisprudencia del Tribunal Constitucional chileno relativa a la función social de la propiedad.

La jurisprudencia constitucional ha evolucionado en las últimas décadas, afirmando que los contratos celebrados por privados están también sujetos a las limitaciones que se derivan de la función social de la propiedad, descartando la intangibilidad contractual. Nuestro propósito es dar cuenta de esta evolución y perfilar el concepto de función social de la propiedad que se desprende de la Constitución. Para ello, nos hemos propuesto el esquema de trabajo que expondremos a continuación.

Comenzaremos por señalar qué es lo que establece hoy nuestra Constitución sobre la función social de la propiedad, para luego realizar un breve recorrido por la evolución constitucional que desembocó en la regulación actual. Después, revisaremos brevemente el derecho comparado en la materia.

A continuación, iremos al cuerpo de este artículo, que es el estudio de la jurisprudencia del Tribunal Constitucional chileno sobre la función social de la propiedad. Comenzaremos por algunas precisiones conceptuales. Primero, diferenciaremos la expropiación de la limitación, en tanto límites al derecho de propiedad, y luego nos referiremos a la llamada expropiación regulatoria. Enseguida, dejaremos en claro -como cuestiones preliminares- que la Constitución no ha definido qué es la función social de la propiedad y que esta es inherente a todo tipo de propiedad. A continuación, ofreceremos un concepto de función social a partir de lo que ha señalado la jurisprudencia constitucional, para luego referirnos a las limitaciones al derecho de propiedad que se derivan de esta función social, definiéndolas positiva y negativamente, y señalando quién es el sujeto encargado de ellas. Hecho lo anterior, haremos un barrido por los criterios a los que se han atendido para resolver si una limitación a la propiedad es o no legítima. Por último, trazaremos algunas conclusiones.

\section{La regulación de la propiedad en la Constitución}

El artículo 19 numeral $24 .^{\circ}$ de Constitución Política de Chile asegura a todas las personas «el derecho de propiedad en sus diversas especies sobre toda clase de bienes corporales o incorporales». En su inciso segundo, dicho numeral establece que «solo la ley puede establecer el modo de adquirir la propiedad, de usar, gozar y disponer de ella y las limitaciones y obligaciones que deriven de su función social». Para la Constitución, la función social de la propiedad «comprende cuanto exijan los intereses generales de

1. Este artículo es producto de la revisión y actualización de una ponencia de las autoras presentada en la cuarta versión del Congreso Estudiantil de Derecho Civil de la Facultad de Derecho de la Universidad de Chile, en marzo del año 2016. El trabajo está basado en una recopilación de jurisprudencia previa realizada por el profesor Carlos Carmona. 
la Nación, la seguridad nacional, la utilidad y la salubridad públicas y la conservación del patrimonio ambiental». Además, el inciso tercero señala:

Nadie puede, en caso alguno, ser privado de su propiedad, del bien sobre que recae o de alguno de los atributos o facultades esenciales del dominio, sino en virtud de ley general o especial que autorice la expropiación por causa de utilidad pública o de interés nacional, calificada por el legislador.

La disposición referida en el párrafo anterior garantiza la protección constitucional del derecho de propiedad tanto sobre bienes corporales como incorporales, pero reconoce a su vez que no se trata de un derecho absoluto, sino que puede ser objeto de limitaciones. Estas limitaciones están dadas, por un lado, por las obligaciones y cargas que derivan de la función social de la propiedad, las que deben ser establecidas por el legislador; y, por otro lado, por la posibilidad que tiene el Estado de privar a un individuo de su derecho de propiedad sobre un bien determinado, por causa de utilidad pública o de interés nacional (expropiación). Entonces, la Constitución de 1980 reconoce como grandes límites al derecho de propiedad la expropiación y la función social de la propiedad. Mientras que la expropiación es una limitación extrínseca, la función social es una limitación intrínseca.

Ya en la Constitución de 1833 se encontraba regulada la expropiación. Dicho texto, en su artículo 12 número 5, establecía el derecho a la inviolabilidad de «todas las propiedades» y señalaba que nadie podía ser privado de su propiedad, "salvo el caso en que la utilidad del Estado, calificada por una lei, exija el uso o enajenación de alguna [propiedad]». Similar era la redacción de la regulación de la expropiación en el texto original de la Constitución de 1925:

Nadie puede ser privado de la [propiedad] de su dominio, ni de una parte de ella, o del derecho que a ella tuviere, sino en virtud de sentencia judicial o de espropiacion por razon de utilidad pública, calificada por una lei.

Esta disposición fue modificada por la reforma constitucional de 1967, según la cual «nadie puede ser privado de su propiedad sino en virtud de ley general o especial que autorice la expropiación por causa de utilidad pública o interés social, calificada por el legislador» (Ley 16.615, 1967: artículo único). ${ }^{2}$

Vemos entonces que tanto en la Constitución de 1833, como en la de 1925 y en la de 1980, la expropiación es la privación del derecho de propiedad de un particular por parte del Estado, por causa de utilidad pública calificada por ley, debiendo el Estado pagar la indemnización correspondiente. Estos elementos sustantivos de la expropiación se mantienen constantes a lo largo de la evolución constitucional; las reformas constitucionales se refieren fundamentalmente a la indemnización que ha de pagarse al particular cuya propiedad fue expropiada.

Cuestión distinta ocurre con el concepto de función social de la propiedad.

2. El extracto citado corresponde al texto reformado de la Constitución Política de 1925 (artículo 10, número 10, inciso cuarto). 


\section{Evolución de la función social de la propiedad desde la Constitución de 1925}

El artículo 10 de la Constitución Política de 1925 «asegura a todos los habitantes de la República: [...] 10. ${ }^{\circ}$ La inviolabilidad de todas las propiedades, sin distinción alguna». Reconoce, sin embargo, que este derecho de propiedad no es absoluto, sino que su ejercicio «está sometido a las limitaciones o reglas que exijan el mantenimiento y el progreso del orden social». Y esto habilita al legislador para «imponerle obligaciones o servidumbres de utilidad pública en favor de los intereses jenerales del Estado, de la salud de los ciudadanos y de la salubridad pública». No había aquí una consagración expresa de la función social de la propiedad, pero supone de todos modos una diferencia respecto de la regulación que hacía suya la Constitución de 1833, que solo hacía referencia a la expropiación, pero no a las limitaciones que el legislador puede imponer al dominio. En la Constitución de 1925 se reconoce constitucionalmente por primera vez en Chile que hay límites y obligaciones asociadas al derecho de propiedad.

El origen de la consagración de la función social en nuestra Constitución se encuentra en la Constitución alemana de Weimar de 1919, que en su artículo 153 señalaba que «la propiedad obliga» y que «su uso ha de constituir al mismo tiempo un servicio para el bien general», y en la Constitución mexicana de 1917, que fue la primera Constitución latinoamericana en incorporar la noción de función social de la propiedad. En su artículo 27, señala, en primer lugar, que:

La propiedad de las tierras y aguas comprendidas dentro de los límites del territorio nacional, corresponde originariamente a la Nación, la cual ha tenido y tiene el derecho de transmitir el dominio de ellas a los particulares, constituyendo la propiedad privada.

Y queda aquí claro que esta Carta Fundamental concibe el origen de la propiedad privada en una decisión soberana de la comunidad políticamente organizada en el Estado, y no como un derecho previo de los particulares que el Estado se limita a reconocer y garantizar. Y, en segundo lugar, a propósito de lo que aquí nos convoca, señala en el mismo artículo que:

La Nación tendrá en todo tiempo el derecho de imponer a la propiedad privada las modalidades que dicte el interés público, así como el de regular el aprovechamiento de los elementos naturales susceptibles de apropiación, para hacer una distribución equitativa de la riqueza pública y para cuidar su conservación.

La Ley 16.615 de reforma constitucional de 1967 modificó la Constitución de 1925 en lo que se refiere a la consagración del derecho de propiedad como garantía constitucional. El nuevo texto de la Constitución garantizaba a todos los habitantes de la República «el derecho de propiedad en sus diversas especies», lo que es una modificación de la literalidad del precepto, ya que el texto constitucional anterior garantizaba la inviolabilidad de «todas las propiedades». 
Si bien en el texto original de la Constitución de 1925 esto ya se insinuaba, con la reforma constitucional de 1967 se incorpora expresamente la noción de función social de la propiedad, al señalarse que la ley «establecerá el modo de adquirir la propiedad, de usar, gozar y disponer de ella y las limitaciones y obligaciones que permitan asegurar su función social y hacerla accesible a todos» (artículo 10, número 10). El ejercicio de los atributos esenciales del dominio será materia de regulación por el legislador, el que está habilitado para tal efecto por la función social de la propiedad, que comprende no solo los intereses generales del Estado y la salud de los ciudadanos y la salud pública, sino también el mejor aprovechamiento de las fuentes y energías productivas en el servicio de la colectividad y la elevación de las condiciones de vida del común de los habitantes. Se amplían entonces las consideraciones de utilidad pública por las que la Constitución le reconoce al legislador la potestad de limitar el derecho de propiedad y sus atributos esenciales, fortaleciéndose la noción de bien común que está detrás del precepto.

Además, esta reforma constitucional agregó:

Cuando el interés de la comunidad nacional lo exija, la ley podrá reservar al Estado el dominio exclusivo de recursos naturales, bienes de producción u otros, que declare de importancia preeminente para la vida económica, social o cultural del país (Ley 16.615, 1967: artículo único). ${ }^{3}$

De este modo, el interés de la comunidad no fundamenta solo que se puedan establecer limitaciones al ejercicio del derecho de propiedad que los particulares tienen sobre determinados bienes, sino también que el legislador establezca que determinados recursos naturales y medios de producción no son susceptibles de apropiación por parte de particulares, quedando su dominio reservado al Estado. Esta última disposición fue modificada por la Ley 17.450 de 1971 de reforma constitucional, que agregó que la ley, además de tener la facultad de reservar al Estado su dominio exclusivo, puede también nacionalizar dichos recursos naturales, bienes de producción u otros.

Vemos entonces que, durante la vigencia de la Constitución de 1925, hubo una evolución progresiva del concepto de función social de la propiedad, otorgándosele un ámbito de aplicación cada vez mayor como una forma de promover el desarrollo del país en diversos aspectos.

Esta situación cambia con la dictación de la Constitución de 1980. En ella se mantiene la decisión constitucional de reconocer la función social de la propiedad como límite a esta misma, pero queda limitada a «cuanto exijan los intereses generales de la Nación, la seguridad nacional, la utilidad y la salubridad públicas y la conservación del patrimonio ambiental» (artículo 19 numeral $24 .^{\circ}$ inciso segundo). Se reducen entonces las causales que comprende.

3. El extracto citado corresponde al texto reformado de la Constitución Política de 1925 (artículo 10, número 10, inciso tercero). 


\section{Derecho comparado}

Resulta pertinente, a su vez, revisar la regulación en el derecho comparado del derecho de propiedad en lo relativo a la expropiación y su función social.

En primer lugar, en lo que a expropiación respecta, las Constituciones regulan con distinto nivel de detalle la indemnización que corresponde. En América Latina, la Constitución argentina asegura al propietario el derecho a recibir una indemnización, sin una calificación, en su artículo 17, inciso primero:

La propiedad es inviolable, y ningún habitante de la Nación puede ser privado de ella, sino en virtud de sentencia fundada en ley. La expropiación por causa de utilidad pública debe ser calificada por ley y previamente indemnizada.

En cambio, hay otras constituciones que sí contienen en su consagración del derecho de propiedad una referencia a cierta fórmula indemnizatoria sustantiva. Entre ellas se cuentan las constituciones de Colombia, Perú y México. La constitución colombiana señala que la indemnización «se fijará consultando los intereses de la comunidad y del afectado» (artículo 58, inciso final); la del Perú establece que la expropiación requiere el "pago en efectivo de indemnización justipreciada» (artículo 70); y la mexicana norma que «el precio que se fijará como indemnización a la cosa expropiada se basará en la cantidad que como valor fiscal de ella figure en las oficinas catastrales o recaudadoras» (artículo 27, numeral 6. ${ }^{\circ}$ ).

Algo similar ocurre con las Constituciones europeas. Algunos ordenamientos contemplan el derecho a indemnización, pero dejan sus pormenores a la ley. Tal es el caso de España, que señala que procede la expropiación «mediante la correspondiente indemnización» (artículo 33.3), y de Italia, que expresa que «la propiedad privada podrá ser expropiada por motivos de interés general en los casos previstos por la ley y mediante indemnización» (artículo 42, inciso segundo). Otros ordenamientos contemplan criterios materiales para la fijación de la indemnización. Por ejemplo, la norma alemana señala que «la indemnización se fijará considerando en forma equitativa los intereses de la comunidad y de los afectados» (artículo 14.3) y en Francia, en la Declaración de los Derechos del Hombre y del Ciudadano, se contempla que el expropiado tiene derecho a una «indemnización previa y justa» (artículo 17).

En segundo lugar, en lo relativo a la función social de la propiedad, esta está presente tanto en el derecho latinoamericano como en el europeo. En nuestro continente, ejemplos de lo anterior son la Constitución brasileña («Se garantiza el derecho a la propiedad; [...] 23. La propiedad privada atenderá a su función social»; artículo 5, número 22), la colombiana («la propiedad es una función social que implica obligaciones»; artículo 58, inciso segundo); la mexicana («La nación tendrá en todo tiempo el derecho de imponer a la propiedad privada las modalidades que dicte el interés público, así como el de regular, en beneficio social, el aprovechamiento de los elementos naturales susceptibles de apropiación, con objeto de hacer una distribución equitativa de la riqueza pública, cuidar de su conservación, lograr el desarrollo equilibrado del país y el 
mejoramiento de las condiciones de vida de la población rural y urbana»; artículo 27, inciso tercero); la costarricense («Por motivos de necesidad pública podrá la Asamblea Legislativa, mediante el voto de los dos tercios de la totalidad de sus miembros, imponer a la propiedad limitaciones de interés social»; artículo 45, inciso segundo) y la boliviana («Toda persona tiene derecho a la propiedad privada individual o colectiva, siempre que ésta cumpla una función social»; artículo 56, número 1).

En Europa ocurre lo mismo. La Constitución española señala que «Se reconoce el derecho a la propiedad privada y a la herencia. 2. La función social de estos derechos delimitará su contenido, de acuerdo con las leyes» (artículo 33.2), mientras que la italiana señala: «La propiedad privada será reconocida y garantizada por la ley, la cual determinará sus modalidades de adquisición y de goce y los límites de la misma, con el fin de asegurar su función social y de hacerla accesible a todos (artículo 42, inciso tercero). Y la Constitución alemana, por su parte, establece: «La propiedad obliga. Su uso debe servir al mismo tiempo al bien común» (artículo 14, número 2).

\section{Jurisprudencia del Tribunal Constitucional de Chile}

\section{Precisiones conceptuales}

\section{Expropiación y limitación}

La expropiación y la limitación, como ya dijimos, son los dos grandes límites al derecho de propiedad que contempla nuestra Constitución. Ahora bien, estas instituciones son conceptualmente distintas. Al respecto, el Tribunal Constitucional ha señalado:

Que la distinción entre privar de propiedad, por una parte y regular o limitar la propiedad, por otra, es una de las que mayor debate han suscitado en la doctrina. A su respecto han debido pronunciarse las jurisdicciones constitucionales más influyentes del mundo. En general, puede decirse que conceptualmente ambas figuras pueden distinguirse, pues un acto de privación tendrá por objeto despojar, quitar, sustraer una determinada propiedad de su titular, mientras el acto regulatorio tendrá por función determinar las reglas a que debe ajustarse el ejercicio del dominio, estableciendo un modo limitado y menos libre de ejercer la propiedad sobre la cosa. (Sentencia del Tribunal Constitucional rol 506-06, 2007: considerando sexto.)

Entonces, en primer lugar, expropiación y limitación son diversas en lo relativo a la causal. La expropiación, de acuerdo con el texto constitucional, tiene su fuente en una "causa de utilidad pública o de interés nacional, calificada por el legislador» (artículo 19 numeral 24. ${ }^{\circ}$ inciso cuarto). $\mathrm{Al}$ respecto, el Tribunal Constitucional ha señalado:

Se expropia por utilidad pública o por el interés general; no como consecuencia de alguna obligación particular que pesa sobre el administrado, ni como producto de alguna sanción que se pretende imponer al mismo. (Sentencia del Tribunal Constitucional, rol 541-06, 2006: considerando décimo.) 
La causal de la limitación, por el otro lado, es la función social de la propiedad, que, según el texto constitucional, «comprende cuanto exijan los intereses generales de la Nación, la seguridad nacional, la utilidad y la salubridad públicas y la conservación del patrimonio ambiental» (artículo 19 numeral 24. ${ }^{\circ}$ inciso segundo).

En segundo lugar, mientras que en la expropiación hay un desplazamiento patrimonial - «expropiar es privar a una persona de la titularidad de un bien o de un derecho»- (Sentencia del Tribunal Constitucional rol 541-06, 2006: considerando décimo), en la limitación no hay tal desplazamiento patrimonial, pues el sujeto cuyo derecho de propiedad es limitado no deja, por ello, de ser dueño - «las limitaciones suponen el establecimiento de determinadas cargas al ejercicio de un derecho, dejándolo subsistente en sus facultades esenciales» (Sentencia del Tribunal Constitucional rol 245-96, 1996: considerando vigésimo segundo).

En tercer lugar, en la expropiación la Constitución garantiza el derecho a una indemnización "por el daño patrimonial efectivamente causado», mientras que para la limitación no se establece indemnización alguna. Al respecto, el Tribunal Constitucional ha dicho:

Así, la diferencia entre una privación y una limitación radica en que la expropiación sustituye la afectación de la privación haciendo desaparecer la vulneración del derecho por parte del legislador, cuestión que no acontece en la limitación [...]. Las limitaciones u obligaciones impuestas por el legislador han de delimitar el derecho de propiedad o sus atributos a partir de la concreción de su función social. (Sentencia del Tribunal Constitucional rol 2299-12, 2014: considerando noveno.)

La jurisprudencia constitucional ha definido los elementos básicos de la expropiación. Así, ha dicho que es una privación de dominio («expropiar es privar a una persona de la titularidad de un bien o de un derecho, dándole a cambio indemnización») (Sentencia del Tribunal Constitucional rol 541-06, 2006: considerando décimo), «el cercenamiento de un derecho afectando su esencia y los atributos que lo identifican» (Sentencia del Tribunal Constitucional rol 2299-14, 2014: considerando octavo). También, ha señalado que es un acto de autoridad unilateral que usa mecanismos de derecho público, y por tanto «los privados no pueden llevarla a cabo [...], le pertenece al Estado»; «se trata de una transferencia coactiva»; "está sujeta a un procedimiento de derecho público»; «es un acto unilateral de la Administración»; «es el ejercicio de una potestad pública» (Sentencia del Tribunal Constitucional, rol 1576-09, 2010: considerandos quinto y séptimo). Asimismo, implica el uso de la potestad expropiatoria, que es «lo que distingue un genuino acto expropiatorio de una vía de hecho» (Sentencia del Tribunal Constitucional rol 1576-09, 2010: considerando séptimo).

Sus requisitos básicos son que requiere una causal —utilidad pública o interés general一, requiere desplazamiento patrimonial — la Constitución habla de «la toma de posesión material del bien expropiado»-y requiere indemnización - «pues junto a la potestad expropiatoria existe la garantía patrimonial para el afectado. De ahí que cons- 
tituya un elemento esencial de ella la indemnización» (Sentencia del Tribunal Constitucional rol 1576-09, 2010: considerando octavo).

\section{Expropiación regulatoria}

Decíamos que una de las consecuencias fundamentales de distinguir entre expropiación y limitaciones al dominio es que, de acuerdo con la interpretación tradicional del numeral $24 .^{\circ}$ del artículo 19 de la Constitución, solo la primera da lugar a indemnización, no así la segunda, ya que en la limitación no hay un desplazamiento patrimonial que deba ser compensado.

Sin embargo, recientemente ha habido jurisprudencia que ha entendido que la diferencia entre expropiación y limitación sería una diferencia de grado, una diferencia cuantitativa y no cualitativa. De acuerdo con esta concepción:

Las limitaciones que la ley puede imponer a la propiedad en razón de su función social - y que no dan lugar a indemnización - se encuentran en un continuo conceptual con las privaciones de la propiedad, que deben ser indemnizadas por constituir una expropiación (Aldunate, 2006: 287).

Podría haber entonces una limitación tan intensa a la propiedad que tendría que ser indemnizada, por equipararse en la práctica a la expropiación. Esta figura se conoce como expropiación regulatoria, y fue introducida a nuestra cultura jurídica desde el derecho estadounidense por la jurisprudencia del Tribunal Constitucional. Así, este tribunal señaló el año 2007:

Si el acto de regulación o de limitación afecta en una magnitud significativa las facultades o atributos esenciales del propietario, este podrá argumentar que se le ha privado del dominio, pues ya no puede hacer las cosas esenciales que este conllevaba. (Sentencia del Tribunal Constitucional rol 505-06, 2007: considerando sexto)

El Tribunal Constitucional ya había recurrido a esta teoría el año 2001:

No solo se produce privación del dominio cuando se le despoja a su dueño totalmente de él o de uno de sus atributos o facultades esenciales, sino, también, cuando ello se hace parcialmente o mediante el empleo de regulaciones que le impidan libremente ejercer su derecho o uno de sus atributos. (Sentencia del Tribunal Constitucional rol 334-01, 2001: considerando decimonoveno)

Se ha señalado asimismo que no admitir en caso alguno indemnización si no hay desplazamiento patrimonial implicaría una desnaturalización de la protección que la Constitución dispensa al derecho de propiedad. El fundamento constitucional que se le ha dado a la procedencia de la indemnización por regulación expropiatoria es que el artículo 19 numeral $24 .^{\circ}$ de la Constitución, al referirse a la expropiación, señala que nadie podrá ser privado de su derecho de propiedad, del bien sobre el que este recae o de «alguno de los atributos o facultades esenciales del dominio». La regulación ex- 
propiatoria, por la intensidad de la afectación al dominio que establece, constituiría tal privación de atributos o facultades esenciales del dominio.

Sin embargo, la tendencia jurisprudencial que acogió la figura de la regulación expropiatoria no logró consolidarse en el tiempo. Pronto el Tribunal Constitucional fue regresando a la tradición ya asentada en el derecho chileno, según la cual la pregunta relevante es si la limitación es legítima atendiendo a ciertos criterios de resolución (mesura y razonabilidad de la limitación, función pública y privilegios involucrados en la actividad, entre otros) o si no lo es. Y es en atención a esta distinción entre limitación y expropiación que el Tribunal Constitucional no ha admitido indemnización por cualquier limitación del derecho de propiedad que prive al particular de algún beneficio. Lo anterior sería, en esa línea, privar de toda operatividad a la función social de la propiedad y desnaturalizarla, ya que

toda regulación o limitación priva al propietario de algo [...], alguna autonomía, privilegio, ventaja o libertad que tenía, desaparece para su titular. Si tuviéramos por propiedad cada aspecto de esa autonomía, privilegio, ventaja o libertad, la regla constitucional que permite limitar la propiedad equivaldría a letra muerta. (Sentencia del Tribunal Constitucional rol 2299-12, 2014: considerando vigésimo cuarto)

Así, tras haber fallado algunas veces acogiendo la doctrina norteamericana de la expropiación regulatoria, el Tribunal Constitucional ya no persiste en ello, y es que no tiene necesidad de hacerlo. Ha desarrollado criterios para determinar si es legítima o no una limitación, y no necesita, entonces, recurrir a una doctrina extranjera para señalar que hay limitaciones desmesuradas que no son legítimas. Estos criterios o razones tienen fundamento en la lectura armónica de los numerales $24 .^{\circ}$ y $26 .^{\circ}$ del artículo 19 de la Constitución Política de la República. ${ }^{4} \mathrm{Si}$ el tribunal tiene ya una doctrina asentada de mesura para determinar la legitimidad de las limitaciones, ¿acaso no está demás importar una doctrina extranjera?

Luego, hay razones sustantivas para sostener que todavía en el caso en que la doctrina importada de la expropiación regulatoria fuese necesaria y útil, su injerto en nuestro sistema sería un tanto forzado. En primer lugar, porque el artículo 18 numeral $24 .^{\circ}$ incisos segundo y tercero de la Constitución reconocen solo tres instituciones: delimitar («sólo la ley puede establecer el modo de adquirir la propiedad, de usar, gozar y disponer...»), limitar («...y las limitaciones y obligaciones que deriven de su función social») y expropiar («nadie puede, en caso alguno, ser privado de su propiedad»). Entre estas tres instituciones no se encuentra la expropiación regulatoria. En segundo lugar, porque la expropiación supone privación, supuesto que no se verifica en la expropiación regulatoria. En tercer lugar, porque no habiendo privación y, por tanto, no habiendo

4. «La seguridad de que los preceptos legales que por mandato de la Constitución regulen o complementen las garantías que ésta establece o que las limiten en los casos en que ella lo autoriza, no podrán afectar los derechos en su esencia, ni imponer condiciones, tributos o requisitos que impidan su libre ejercicio» (artículo 19 numeral 26. ${ }^{\circ}$; el énfasis es nuestro). 
expropiación, no hay derecho a indemnización («El expropiado [...] tendrá siempre derecho a indemnización por el daño patrimonial efectivamente causado», inciso tercero). En cuarto lugar, porque las limitaciones y obligaciones tienen como límite «cuanto exija» la función social. En quinto lugar, porque la construcción de la expropiación regulatoria sobre el artículo 19 numeral $24 .^{\circ}$ que se pretende dejaría inútil al artículo 19 numeral $26 .^{\circ}$. En sexto lugar, porque implicaría una restricción o cortapiso a la labor del legislador que regula: ¿acaso el cambio regulatorio intenso será razón suficiente para reclamar y obtener indemnizaciones?

No obstante lo anterior, en algunas ocasiones el Tribunal Constitucional parece haber vuelto a recurrir a una figura similar a la expropiación regulatoria. Así ocurrió en el caso Curtidos BAS, en que se discutía el traslado de una industria presuntamente «mal ubicada» en los términos del artículo 62 de la Ley General de Urbanismo y Construcciones (que causa molestias o daños al vecindario). En este caso, el Tribunal Constitucional afirmó:

El susodicho «traslado» no implica que el establecimiento comprometido tenga que desplazarse, desde el lugar en que se encuentra radicado, a algún determinado barrio industrial. Se trata de una orden de retiro que para el afectado implica -en realidaduna ablación, esto es, la pérdida del derecho a permanecer en el inmueble de su propiedad, para seguir desarrollando las mismas actividades a que él lícitamente las destinó. Privación que se produce aunque formalmente conserve el título de propietario [...]. Así, en la especie toma forma una supresión virtual de las prerrogativas inherentes al dominio, en circunstancias que la Constitución (artículo 19 numeral 24..$^{\circ}$ inciso tercero), a los efectos de exigir que medie una expropiación, entiende que la privación del dominio no solo acontece cuando se quita o despoja al dueño de lo suyo, en su totalidad, sino también cuando al titular - aun conservando nominativamente tal carácter- se le desposee, parcialmente, de alguno de los atributos o facultades esenciales que caracterizan la propiedad. (Sentencia del Tribunal Constitucional rol 2684-24, 2015: considerando vigésimo segundo)

\section{Cuestiones preliminares}

a) La Constitución no ha definido la función social. En primer lugar, cabe señalar que, pese a que la Constitución se refiere a la función social de la propiedad, no define qué es lo que tenemos que entender por tal concepto, sino que solo señala cuáles son los elementos que la componen, a saber, los intereses generales de la Nación, la seguridad nacional, la utilidad y salubridad públicas y la conservación del patrimonio ambiental.

Hay algunas referencias a la función social de la propiedad en el proceso de elaboración de la Constitución de 1980 (Sentencia del Tribunal Constitucional rol 24596, 1996). En el Memorándum de 16 de agosto de 1978, dirigido por la Comisión de Estudios de la Nueva Constitución al Presidente de la República, se señala por una parte que «la función social es inherente al derecho de propiedad y está implícita en él», se reconoce que hay intereses colectivos en armonía con los cuales debe ejercerse 
el derecho de propiedad. Y, en este sentido, las limitaciones al dominio «constituyen la expresión jurídica de los deberes anexos al dominio» (Comisión de Estudios de la Nueva Constitución, 1978), los que están dados precisamente por la función social que cumple la propiedad.

No obstante lo anterior, para determinar cuál es el contenido específico del concepto de función social de la propiedad recurriremos a la doctrina y fundamentalmente a la jurisprudencia, que ha transitado por sucesivas etapas.

b) Primera etapa: teoría de los derechos adquiridos e intangibilidad contractual. La llamada «teoría de los derechos adquiridos» distingue entre meras expectativas y derechos adquiridos, con el objetivo de afirmar que solo las primeras, no así los segundos, pueden verse afectados por modificaciones legislativas. Esto porque el derecho de propiedad que su titular tiene sobre estos derechos adquiridos sería un derecho que se encuentra protegido por la garantía constitucional del artículo 19 numeral $24 .{ }^{\circ}$ de la Constitución. Esto implica, paradigmáticamente, que el legislador no puede afectar los derechos que emanan de los contratos, ni tampoco la regulación a la que estos están sujetos. Quienes sostienen esta teoría se basan en la disposición contenida en el artículo 22 de la Ley sobre Efecto Retroactivo de las Leyes de 1861, según la cual se entienden incorporadas al contrato las leyes vigentes al momento de su celebración.

La formulación clásica de esta doctrina la expresa claramente Luis Claro Solar:

Los efectos del contrato son regidos por la ley en vigencia a la época de su perfeccionamiento, y están al abrigo de un cambio de legislación. Ellos dependen exclusivamente de la voluntad de los contratantes, aunque esta voluntad no se haya manifestado expresamente, pues la ley la suple o la interpreta, en el sentido de que cuando las partes no han determinado completamente los efectos que el contrato debe producir, se considera que han querido referirse a la ley en este punto, y no podría ser a otra ley que aquella que existía a la época del contrato. Hacerlos regir por una nueva ley, que los contratantes no han podido tener en vista al contratar, sería sustituir una nueva convención a la que las partes han celebrado, y despojarlas, al mismo tiempo, de derechos adquiridos (Claro Solar, 1945: 79-80).

Esta teoría de los derechos adquiridos, en la que se funda la intangibilidad de los contratos, tuvo acogida en un primer momento en la jurisprudencia del Tribunal Constitucional. Así, este tribunal señaló el año 1995, en el famoso caso de la «deuda subordinada», que:

El hecho de celebrar el contrato [...] determinó indefectiblemente la incorporación al patrimonio [...] de los derechos establecidos en la legislación vigente a la época de su adquisición. Fue efectivamente aquel hecho, la circunstancia fáctica con aptitud suficiente para traer como consecuencia la incorporación inmediata de un derecho de carácter patrimonial, protegido por la garantía consagrada en el artículo 19 numeral $24{ }^{\circ}$ de la Constitución Política y, por lo tanto, estableciendo una limitación a las atribuciones del legislador en el sentido de carecer de facultades para alterarlo, menosca- 
barlo o anularlo por una norma posterior. (Sentencia del Tribunal Constitucional rol 207-95, 1995: considerando sexagésimo tercero)

De acuerdo con esta teoría, entonces, los contratos se vuelven intangibles y queda vedado al legislador afectar la regulación contractual ya establecida por las partes, pues ello implicaría una expropiación en el sentido del numeral $24 .^{\circ}$ del artículo 19 de la Constitución, que requeriría por tanto calificación de utilidad pública y sería el antecedente de un derecho a indemnización. Esto hace que toda modificación legislativa que afecte la regulación de algún tipo de contrato solo pueda operar respecto de los contratos celebrados con posterioridad a la entrada en vigencia de dicha ley. Esto transforma el derecho de propiedad que se tiene sobre los derechos que emanan de los contratos en un derecho de propiedad absoluto, que no admite ser limitado por el legislador.

c) Segunda etapa: la función social se aplica a todo tipo de propiedad. En la jurisprudencia de los últimos años, el Tribunal Constitucional ha abandonado la teoría de la intangibilidad contractual y ha admitido que, al igual que al derecho de propiedad que se tiene sobre los bienes corporales, al derecho de propiedad sobre bienes incorporales o «créditos» (típicamente, los derechos que emanan de los contratos) se le aplica también la función social de la propiedad, y admite por tanto limitación por parte del legislador.

Como vimos a propósito de la evolución constitucional del derecho de propiedad, ya en la Constitución de 1833 se hablaba de la inviolabilidad de «todas las propiedades», redacción que se mantuvo en la versión original de la Constitución de 1925. El año 1967 se modificó la literalidad de la disposición, pasando a señalarse que la Constitución asegura el derecho de propiedad «en sus diversas especies», y es esta la redacción del texto constitucional actualmente vigente. Así, vemos que ya desde el siglo XIX se reconocía que la propiedad no es solo una, sino que hay varios tipos de propiedad. La principal diferencia la encontramos entre la propiedad que se tiene sobre bienes corporales y aquella que se tiene sobre bienes incorporales, lo que fue también recogido en el Código Civil, que define la propiedad como «el derecho real en una cosa corporal, para gozar y disponer de ella arbitrariamente; no siendo contra la ley o contra derecho ajeno» (artículo 582), e inmediatamente después señala que «sobre las cosas incorporales hay también una especie de propiedad» (artículo 583). No obstante estas diferencias, artículo 19 numeral $24 .^{\circ}$ de la Constitución, a la hora de garantizar constitucionalmente el derecho de propiedad, no hace distinción en la protección que se le dispensa a uno y otro tipo de propiedad.

En este sentido, al ser el mismo estatuto de protección el que se aplica a las diversas especies de propiedad, no hay tampoco diferencias en materia de las limitaciones y obligaciones que pueden imponerse en razón de la función social. El Tribunal Constitucional ha dicho recientemente que, ya que la Constitución no distingue

esta autorización, dada por el constituyente al legislador para disponer limitaciones y obligaciones a la propiedad, a condición de que se deriven de su función social [...], se aplica, prima facie, a todas las clases y especies de propiedad, incluyendo los bienes incorporales, sin excluir los que nacen del contrato. [Que] al establecer reglas para 
balancear los legítimos intereses públicos con la defensa de la propiedad privada, la Carta Fundamental establece unos mismos criterios, cualquiera sea el origen o el título de la propiedad adquirida. [...] [ Y que] tampoco hay nada en la naturaleza de derecho de propiedad sobre bienes incorporales que impida limitarlos en razón de la función social de la propiedad. (Sentencia del Tribunal Constitucional rol 506-06, 2007: considerando quinto)

Asimismo, el año 2006 el Tribunal Constitucional niega que pueda reconocerse como legítima la pretensión de alegar propiedad sobre la legislación vigente al momento de la celebración del contrato (Sentencia del Tribunal Constitucional rol 467-06, 2006), lo que es evidente pues ello sería desconocer la naturaleza de la labor legislativa y admitir que los particulares, por un pacto entre ellos, que tiene rango infralegal, pueden sustraerse de la ley. Lo mismo ha vuelto a señalar en la Sentencia rol 1452-09, de 2010, al afirmar que no hay propiedad sobre los beneficios tributarios que establece la legislación, y en múltiples fallos del año 2012 (Sentencias del Tribunal Constitucional roles 1863-10, 1986-11, 1991-11, 1992-11 y 1993-11, 2012). Esto es reforzado a su vez por la idea de que el legislador, si bien no puede privar a un particular de su derecho de propiedad sino por expropiación, sí puede regular las condiciones de ejercicio de ese derecho, claro está, mientras no afecte el derecho en su esencia, como garantiza artículo 19 numeral 26. ${ }^{\circ}$ de la Constitución). Así, el Tribunal Constitucional ha dicho que

sobre tales condiciones de ejercicio no puede existir ningún derecho adquirido, ni menos, un supuesto derecho a la 'estabilidad' o 'inmutabilidad', pues ellas tienen carácter normativo; son, por lo mismo, indisponibles para los particulares. (Sentencia del Tribunal Constitucional rol 1361-09, 2009: considerando sexagésimo cuarto) ${ }^{5}$

Esta tendencia jurisprudencial concluye, por tanto, que no hay intangibilidad contractual en nuestro ordenamiento, sino que el legislador puede modificar la regulación que rige el contrato y las condiciones de ejercicio de los derechos que de él emanan, respetando el derecho en su esencia. Así lo ha dicho expresamente el Tribunal Constitucional, al señalar que

es un límite con fundamento constitucional el que se pueda fundar en la función social de la propiedad, conforme a las exigencias de la utilidad pública. Los derechos de propiedad sobre cosas incorporales que nacen de contratos entre privados no están inmunes a ser limitados o regulados, en conformidad a la Constitución. (Sentencia del Tribunal Constitucional rol 505-06, 2006: considerando quinto)

Esta línea jurisprudencial del Tribunal Constitucional fue reafirmada en su Sentencia rol 1309-09, de 2010, a propósito de la posibilidad de limitar en razón de su función social el derecho de propiedad que los particulares tienen sobre las aguas. En esta oportunidad, concluyó:

5. Reafirmado en (Sentencia del Tribunal Constitucional rol 3069-16, 2016). 
La Carta Fundamental establece los mismos criterios limitativos, cualquiera sea el bien objeto del derecho de propiedad adquirido y que, en definitiva, es a esta Magistratura a quien le corresponde precisar, en esta sede de control, hasta dónde la ley, por esta vía, puede limitar el derecho de propiedad o imponerle obligaciones que no importen transgredir el estatuto constitucional de este derecho. (Sentencia del Tribunal Constitucional rol 1309-09, 2010: considerando cuarto)

Es indiscutido, por lo tanto, que la función social se aplica a todo tipo de propiedad, incluyendo aquella que recae sobre bienes incorporales como son los derechos que emanan de los contratos, $y$, como se vio, no hay tampoco fundamento constitucional para sostener lo contrario. Sin embargo, y como se verá hacia el final del trabajo, el Tribunal Constitucional en un fallo reciente parece retroceder un paso hacia la teoría de los derechos adquiridos -y no deja de ser curioso que esta decisión la fundamente haciendo referencia a votos de minoría de fallos anteriores-, al afirmar que

las limitaciones al dominio deben ser armónicas con la seguridad jurídica que tiene que contener el ordenamiento jurídico en términos que no afecten el contenido esencial de la propiedad, estableciéndose normas jurídicas que contengan condiciones estables que conlleven a situaciones de certeza. (Sentencia del Tribunal Constitucional rol 5172-18, 2019: considerando vigésimo sexto)

\section{Concepto de función social de la propiedad}

La función social de la propiedad se traduce en obligaciones y limitaciones, tal como señala la norma constitucional (artículo 19, numeral 24, inciso $2^{\circ}$ ). ${ }^{6}$ Estas expresiones, obligaciones y limitaciones, no son extrañas en nuestro texto constitucional. De hecho, estas y otras similares son usadas por el constituyente a lo largo de todo el texto constitucional. Así, en el mismo artículo 19 contamos con expresiones afines como restringir (numerales $3 .^{\circ}, 7 .^{\circ}$ y $\left.8 .^{\circ}\right)$, perturbar $\left(3 .^{\circ}\right)$, condición o condiciones $\left(6 .^{\circ}\right.$ y $\left.19 .^{\circ}\right)$, requisitos $\left(11 .^{\circ}\right.$ y $\left.17 .^{\circ}\right)$, cargas $\left(20 .^{\circ}\right)$, y regular $\left(21 .^{\circ}\right)$. A su vez, fuera del artículo 19 , la limitación al legislador no es extraña en nuestra Constitución. El legislador se encuentra limitado por el artículo 19 numeral 26. ${ }^{\circ}$, pues debe respetar los derechos en su esencia; por el artículo 5, que reconoce los derechos esenciales que emanan de la naturaleza humana como límite a la soberanía; en los artículos 63, 32 y 93, que limitan cuáles son las materias de ley; en el artículo 66, que se establece cuáles son los quórum a los que se debe atener para legislar; en artículo 69, que acota la labor legislativa a las ideas matrices; en los artículos 55 y 74, que norman el procedimiento legislativo; en el artículo 93, que contempla el control al legislador del Tribunal Constitucional. Como vemos, limitar no es una excentricidad en la Constitución.

Los requisitos de las obligaciones y limitaciones en el artículo 19 numeral $24 .^{\circ}$ son tres: primero, la reserva de ley («sólo la ley»); segundo, la proporcionalidad («[la fun-

6. «Sólo la ley puede establecer [...] las limitaciones y obligaciones que deriven de su función social» 
ción social] comprende cuanto exijan...»); y tercero, la relación que debe existir entre la limitación u obligación y la función social («limitaciones y obligaciones que deriven de su función social»).

La propia Constitución contempla, a su vez, un concepto amplio de la función social de la propiedad en el artículo 19 numeral $244^{\circ}$, y una regulación concreta de la misma en la propiedad minera. Esta última es un régimen especial en el que no viene al caso detenerse más que para decir que la función social de la propiedad es un concepto típicamente constitucional que convoca al resto del ordenamiento jurídico para su desarrollo. A diferencia de lo que ocurre con la función social de la propiedad en general, en el caso de la función social de la propiedad minera sí contamos con este desarrollo especial en la propia Constitución. Por ejemplo, la Constitución señala que «el Estado tiene el dominio absoluto, exclusivo, inalienable e imprescriptible de todas las minas», que "corresponde a la ley determinar qué sustancias [...] pueden ser objeto de concesiones de exploración o de explotación», y que esta concesión «obliga al dueño a desarrollar la actividad necesaria para satisfacer el interés público que justifica su otorgamiento» (artículo 19 numeral 24. ${ }^{\circ}$ inciso séptimo), y además establece causales de caducidad y extinción del dominio sobre la concesión. Sin embargo, en el caso de la función social de la propiedad en general, no contamos con ello. Esa es una de las razones por las cuales es tan relevante lo que la jurisprudencia constitucional tenga que decir sobre la función social.

La función social es inherente al derecho de propiedad. Esto se aprecia en la propia redacción de la norma constitucional: «obligaciones y limitaciones que deriven de $s u$ función social». En este sentido, el Tribunal Constitucional ha dicho que la función social de la propiedad significa que la propiedad

tiene un valor individual y social, por lo que debe estar al servicio de la persona y de la sociedad. La Constitución alemana dice: 'la propiedad obliga', para hacer notar que el dominio, además de conferir derechos, impone deberes y responsabilidades a su titular. Estos deberes y responsabilidades del propietario que armonizan los intereses del dueño y de la sociedad puede decirse que constituyen la función social de la propiedad. (Sentencia del Tribunal Constitucional rol 245-96, 1996: considerando vigésimo quinto)

Más recientemente, ha dicho que

la función social de la propiedad es la que permite equilibrar el interés privado que alimenta y orienta el ejercicio del haz de derechos que la constituyen y el interés público que justifica su protección como derecho fundamental (Sentencia del Tribunal Constitucional rol 2643-13, 2015: considerando sexagésimo).

Y, aún más enfáticamente, ha señalado:

De este modo no podemos cuestionar per se la regulación que el legislador efectúe de diversas instituciones que puedan importar una limitación del derecho de propiedad 
individualmente conceptuado. Es más, incluso se puede arribar a la conclusión de que constituye un error el concebir este derecho en esa única dimensión, olvidando que también se encuentra provisto de una faz social, que es inherente al mismo y que si bien se ejerce en los términos y bajo las formas que el ordenamiento jurídico contempla, de modo de hacer armónica la convivencia de ambas dimensiones, en caso alguno puede considerarse como ajena al derecho mismo o como contrario a su ejercicio, pues la propiedad supone ser ejercida por su titular teniendo especial consideración por esta función social. (Sentencia del Tribunal Constitucional rol 3086-16, 2017: considerando vigésimo séptimo)

Asimismo, ha entendido que «el derecho de propiedad se integra no solo con atributos y facultades esenciales vinculadas a su ejercicio, sino que también conlleva deberes para que aquél sea legítimo y no abusivo». (Sentencia del Tribunal Constitucional rol 3345-17, 2018: prevención del voto de mayoría, considerando cuarto)

Humberto Nogueira Alcalá, por su parte, y en el mismo sentido que el ya mencionado principio de la Constitución alemana según el cual «la propiedad obliga», señala que «la propiedad entraña obligaciones, su uso debe estar al servicio del bien común, que es prevaleciente frente al interés particular» (Nogueira Alcalá, 2010: 182).

La inclusión explícita de la función social de la propiedad en nuestro ordenamiento constitucional, con la reforma constitucional de la Ley 16.615, de 1967, se entiende como una forma de conciliar los intereses individuales y los intereses colectivos que conviven en el ejercicio del derecho de propiedad y dar preponderancia a los segundos respecto de los primeros. En este sentido, Pedro Jesús Rodríguez ha dicho que el profundo sentido de esta reforma fue

reconocer que en el ejercicio de la propiedad privada está comprometido el interés público y que puede ser distinto y ajeno al del propietario, y aun contrapuesto, cuando proviene de aspiraciones y urgencias colectivas [y] someter la propiedad privada a los requerimientos colectivos, mediante sanción ulterior de leyes que, partiendo de la limitada, configuraron el derecho social de propiedad privada (Rodríguez, 1972: 117).

Reforzando esta idea de la función social de la propiedad como conciliación de los intereses colectivos y los intereses particulares que están en juego en el ejercicio del derecho de propiedad, José Luis Cea afirma que la función social de la propiedad

es el resultado de la correcta aplicación de una forma o ecuación jurídico-social, que permite conciliar el ejercicio del derecho de propiedad por su dueño, de un lado, con las necesidades del mantenimiento y el desarrollo de la comunidad, de otro. [...] [Y es por lo mismo] expresión del principio de solidaridad, por su estrecha vinculación con la contribución que el dominio tiene que otorgar a la satisfacción de los intereses generales en la sociedad política y a la realización concreta del bien común en ella (Cea, 2012: 574-575).

Asimismo, el Tribunal Constitucional ha señalado que las limitaciones que se derivan de la función social de la propiedad son intrínsecas a ella, por oposición a las priva- 
ciones o expropiaciones, que son limitaciones extrínsecas. Por esto es que tales limitaciones no conlleven indemnización para el particular que soporta la limitación, ya que

esta concretización legislativa de la dimensión social de la propiedad implica reducir algunas de las posibilidades de actuación individual del propietario, pero en cuanto limitación u obligación que es consustancial a su derecho de propiedad, no generando indemnización, puesto que, teóricamente, no hay daño que lamentar. (Sentencia del Tribunal Constitucional rol 2299-12, 2014: considerando octavo)

\section{Las limitaciones}

\section{Cómo se definen las limitaciones}

Las limitaciones al dominio pueden ser definidas de dos formas. En primer lugar, pueden ser definidas positivamente. En este sentido, el Tribunal Constitucional ha dicho que «suponen el establecimiento de determinadas cargas al ejercicio de un derecho, dejándolo subsistente en sus facultades esenciales» (Sentencia del Tribunal Constitucional rol 245-96, 1996: considerando vigésimo segundo).

Pero, por otra parte, las limitaciones también pueden ser definidas negativamente, diferenciando la limitación de la privación. En ese sentido, el mismo tribunal ha dicho:

Un acto de privación tendrá por objeto despojar, quitar, sustraer una determinada propiedad de su titular, mientras el acto regulatorio tendrá por función determinar las reglas a que debe ajustarse el ejercicio del dominio, estableciendo un modo limitado y menos libre de ejercer la propiedad sobre la cosa. (Sentencia del Tribunal Constitucional rol 505-06, 2007: considerando sexto)

Sobre este punto ya nos hemos referido en profundidad.

\section{Reserva de ley}

La Constitución señala que solo la ley puede establecer obligaciones inherentes al dominio y cuyo fundamento es la función social. Una primera cuestión es qué tan preciso debe ser el legislador al establecer estas limitaciones. El Tribunal Constitucional ha dicho:

Establecer una obligación es crearla, instituirla o introducirla, por vez primera, en nuestro ordenamiento jurídico, cumpliendo así el legislador con el carácter innovador que se predica, en la doctrina, como uno de los rasgos matrices de la ley en el derecho positivo [...]. Al legislador le corresponde normar, con amplitud y profundidad, todo cuanto la certeza o seguridad jurídica exige en relación con el establecimiento y configuración de las obligaciones que se imponen al dominio con motivo de la función social que ha de servir [...]; presupone, lógica e ineludiblemente, que el legislador no se limite a ello sino que, además, la configure en sus aspectos y elementos definitorios o característicos, trazando, con adecuada densidad normativa, en qué consiste el deber 
que impone, cuál es el motivo de función social que lo justifica, cuáles son sus delimitaciones, sobre la base de qué supuestos fácticos se torna procedente exigirla, cuál es la autoridad competente para llevarla a efecto y controlarla, a quiénes y por qué motivos se les exime de ella, etc. (Sentencia del Tribunal Constitucional rol 370-03, 2003: considerandos trigésimo, trigésimo primero y trigésimo cuarto)

Luego, la magistratura expresa que la limitación está encargada al legislador en sentido estricto:

La fuente exclusiva que determina las obligaciones o limitaciones sobre la propiedad es la determinación del legislador. Ello no obsta a la colaboración reglamentaria en dimensiones accesorias. (Sentencia del Tribunal Constitucional rol 2299-12, 2014: considerando décimo)

Lo anterior es especialmente relevante, pues el legislador debe establecer estas limitaciones con precisión suficiente, de modo que efectivamente sea la decisión legislativa la que imponga la limitación y no la arbitrariedad de la autoridad administrativa. En este sentido, el Tribunal Constitucional ha afirmado que

es esta delimitación legal lo que asegura, efectivamente, que la autoridad administrativa realice una concreción adecuada y razonable de las referidas condiciones habilitantes (Sentencia del Tribunal Constitucional rol 2684-14, 2015: considerando decimoséptimo).

Entonces, es importante considerar el importante rol al que el legislador está llamado cuando de propiedad se trata. La Constitución de 1980 no contempla un modelo propio de propiedad, por el contrario, se refiere a ella con la vaga expresión «el derecho de propiedad en sus diversas especies». No habiendo un modelo constitucional de propiedad, es la ley la llamada a configurarlo. Así lo reconoce el texto mismo cuando dice que «sólo la ley puede establecer el modo de adquirir la propiedad, de usar, gozar y disponer de ella y las limitaciones y obligaciones que deriven de su función social» (artículo 19 numeral $24 .^{\circ}$ inciso segundo). Luego, estas limitaciones, que serán definidas por el legislador, tienen un amplio margen ( [la función social comprende] cuanto exijan...») y acarrean indemnización. Así, podemos sostener que el modelo de propiedad constitucional contenido en el artículo 19 numeral $24 .^{\circ}$ requiere complementación legal.

Es probable que lo anterior se explique porque la Constitución de 1980 fue redactada con el trauma de la Unidad Popular. Así, la Junta Militar se preocupó de regular con especial recelo la expropiación, pensando en la Reforma Agraria y en el control estatal de los medios de producción. Y en esta línea, reforzó las garantías en favor del expropiado, en lo relativo al monto y al pago de la indemnización, reformó el hito de la toma de posesión de la cosa por parte del Estado y también el proceso de reclamación por el monto de la indemnización. Sin embargo, la función social de la propiedad quedó consagrada en términos similares, aunque no idénticos, a los de la Constitución en su redacción vigente en 1971, de modo que la garantía constitucional de la propiedad limita en menor medida al Estado regulador, característico de los años noventa en adelante. 


\section{Criterios de resolución}

La pregunta central ahora es cuándo las limitaciones establecidas por el legislador son compatibles con las garantías consagradas en la Constitución. En este contexto, el Tribunal Constitucional ha desarrollado una serie de criterios para definir si una limitación es legítima o no, los que expondremos a continuación.

\section{¿Son mesuradas y razonables?}

Para ser legítima, la limitación a la propiedad debe ser mesurada y razonable. Así lo ha sostenido el Tribunal Constitucional en reiteradas oportunidades. En el caso de la franja televisiva, señaló:

[Puede la ley] imponer obligaciones y limitaciones mesuradas y razonables como son las que las normas del proyecto contemplan. Lo anterior se justifica plenamente tanto como una justa contrapartida al derecho selectivo que se otorga. (Sentencia del Tribunal Constitucional rol 56-88, 1988: considerando duodécimo)

Este criterio ha sido atendido sostenidamente, lo que se ve en el uso de expresiones tales como «razonable» (Sentencia del Tribunal Constitucional rol 253-97, 1997: considerando noveno); «magnitud del gravamen [...] no debe causar daños innecesarios [...], [debe ser] proporcionado» (Sentencia del Tribunal Constitucional rol 1141-o8, 2009: considerando decimonoveno); «medio necesario, o al menos adecuado, para alcanzar un propósito constitucionalmente legítimo, que queda comprendido en la función social de la propiedad» (Sentencia del Tribunal Constitucional rol 1141-08, 2009: considerando vigesimosexto).

\section{¿Causa daño la limitación?}

La limitación, en principio, no causa daño. Este rasgo es, como vimos, uno de los que la distingue de la expropiación. El Tribunal Constitucional señala:

Esta concretización legislativa de la dimensión social de la propiedad implica reducir algunas de las posibilidades de actuación individual del propietario, pero en cuanto limitación u obligación que es consustancial a su derecho de propiedad, no generando indemnización, puesto que, teóricamente, no hay daño que lamentar. (Sentencia del Tribunal Constitucional rol 2299-12, 2014: considerando octavo)

Además, el Tribunal Constitucional ha exigido que la ley, al establecer una limitación, no omita «elementos que contribuirían a mitigar los efectos intensamente gravosos que conlleva la ejecución de tal medida» (Sentencia del Tribunal Constitucional rol 2684-14, 2015: considerando vigésimo séptimo). 


\section{¿Desnaturaliza bienes jurídicos?}

La limitación debe propender a la no desnaturalización de bienes jurídicos. Así, la magistratura constitucional ha mencionado este criterio para afirmar la legitimidad de aquellas limitaciones que el legislador establece precisamente para proteger el sentido genuino de un bien jurídico. Así se ha pronunciado al menos en dos ocasiones al referirse al acceso a las playas, afirmando:

En razón de la función social que debe cumplir el ejercicio del derecho de dominio la autoridad, en este caso el legislador, puede regular el acceso a dichos bienes, a través de los predios colindantes, para que no se desnaturalice el concepto de que son de la Nación toda. (Sentencia del Tribunal Constitucional rol 245-96, 1996: considerando vigésimo octavo)

Y que la innovación normativa «es un medio necesario del que se vale el legislador para que un bien nacional sea efectivamente de uso público». (Sentencia del Tribunal Constitucional rol 1215-08, 2008: considerando vigésimo quinto)

\section{¿La actividad lleva envuelta alguna función pública?}

Para determinar si una limitación es legítima o no, se debe considerar si la actividad que se regula envuelve o no una función pública.

El Tribunal Constitucional ha dicho, para declarar lícita la franja televisiva el año 1988, que

los canales de televisión cumplen una verdadera función de utilidad pública y como lo dice el artículo 1 de la Ley 17.377, 'como medio de difusión han de servir para comunicar e integrar el país'. (Sentencia del Tribunal Constitucional rol 56-88, 1988: considerando décimo)

En el mismo sentido, respecto de contratos que pasaban de ser de precio libre a precio regulado, ha señalado que el legislador puede

exhibir razones derivadas de exigencias de utilidad pública, para disponer, para lo futuro, un nuevo sistema de precios a fin de disminuir riesgos de daños a la población que apreció como severos [...]. Ello justifica limitaciones y regulaciones a la propiedad [...], el legislador precisamente estaba persiguiendo un fin de utilidad pública [...], puede legítimamente disponer un nuevo sistema tarifario que altera, para lo futuro, el sistema de precios [...], aunque con ello afecte los derechos establecidos en un contrato válidamente celebrado. (Sentencia del Tribunal Constitucional rol 506-06, 2007: considerando séptimo)

Siguiendo la misma línea, respecto de la ampliación de una «zona típica» geográfica, señaló que

la conservación del patrimonio ambiental del país y también de su patrimonio cultural [...], conduce inequívocamente a sostener que, en la especie, se ha configurado 
una limitación legítima al ejercicio del derecho de propiedad. (Sentencia del Tribunal Constitucional rol 2299-12, 2014: considerando decimoséptimo)

En este mismo sentido, más recientemente, en el requerimiento de inaplicabilidad por inconstitucionalidad sobre la Fábrica Bellavista Oveja Tomé, que gozó de connotación mediática nacional, el Tribunal Constitucional afirmó:

Toda actividad económica debe necesariamente armonizarse con el marco fundamental y obligatorio consagrado en la Constitución y, consiguientemente, el denominado orden público económico debe respetar y conciliarse en forma con los derechos que la misma Constitución asegura a todas las personas, no pudiendo desconocer dentro de estas garantías, las vinculadas a la función social de la propiedad y la Constitución cultural, que como ya se manifestó oportunamente tienen como objetivo el bienestar de la sociedad en su conjunto. (Sentencia del Tribunal Constitucional rol 3086-16, 2016: considerando trigésimo segundo)

\section{¿Tiene la actividad privilegios?}

Luego, es adecuado atender a si la actividad en cuestión goza de una condición de privilegio. Al referirse al traslado de redes para empresas de servicio público, mencionó:

También la limitación cumple el criterio de tener en cuenta las limitaciones en el contexto de privilegios que pueda disfrutar el afectado [...]. Un concesionario puede usar gratuitamente y de modo exclusivo, un pedazo de un bien nacional de uso público, un bien que es de todos y que, de no mediar el permiso, podrían usar todos [...], tienen una serie de privilegios [...] y facultades que les permiten imponer obligaciones a particulares, incluso más intensas que la que se cuestiona en este requerimiento [...], para exigir a los usuarios que soliciten servicio dentro del área de concesión, un aporte financiero reembolsable para ejecutar ampliaciones de capacidad, o para la extensión de las instalaciones existentes [...] y el derecho a imponer servidumbres. [...]. Ambas figuras son semejantes al traslado de redes. En el caso sub lite, la autoridad, como consecuencia de administrar la faja adyacente a los caminos públicos y con el propósito de garantizar un mejor libre tránsito, dispone su traslado. (Sentencia del Tribunal Constitucional rol 1863-10, 2012: considerando quincuagésimo noveno)

\section{¿Provoca la limitación beneficios para la actividad?}

Cuando el Tribunal Constitucional tuvo que resolver un requerimiento presentado respecto del porcentaje de terrenos que el urbanizador debe destinar y donar para áreas verdes y equipamiento comunitario, señaló:

Las cesiones de terrenos gratuitas razonables, y estas lo son como se verá más adelante, inherentes a toda urbanización, lejos de constituir un daño patrimonial para el dueño procura un beneficio pecuniario para él, pues el valor de los terrenos urbanizados, es superior al valor de dichos terrenos sin urbanizar [...], las cesiones gratuitas 
se efectúan o entran en escena en el caso que el titular del dominio, por su propia y libre voluntad resuelva urbanizar, mal podría entonces siquiera pensarse que afecten el derecho de propiedad que la Constitución le asegura, ya que resultaría absurdo que el propietario persiguiera causarse un daño patrimonial a sí mismo; [...] las destinaciones gratuitas en estudio, por el contrario, robustecen el derecho de propiedad. (Sentencia del Tribunal Constitucional rol 253-97, 1997: considerando décimo)

En el mismo sentido se pronunció sobre el pago por las compañías de seguros de los accidentes que sufran bomberos en actos de servicios, al preguntarse «[si] los motivos del legislador aparecen respaldados, por ejemplo, con datos, o con razones aceptables $\mathrm{y}$ atendibles, $\mathrm{y}$ si se han tomado en cuenta todos los factores relevantes» (Sentencia del Tribunal Constitucional rol 1295-08, 2009: considerando nonagésimo octavo). En este sentido, el Tribunal Constitucional ha sostenido:

El beneficio que la actividad de bomberos reporta a los sujetos gravados por los artículos 3 y 4 del DL 1757, es evidente. Por de pronto, la asociación entre el surgimiento histórico de las Compañías de Seguros y los bomberos, analizada en otra parte de esta sentencia, es reveladora de este vínculo. Enseguida, los bomberos intervienen, por una parte, previniendo incendios. Ellos deben informar las condiciones de seguridad de ciertas construcciones, para evitar siniestros. Por la otra, actúan apagando incendios, o sea, bajando el costo de lo que la Compañía debe pagar al asegurado. Además, informan de las causas del incendio, contribuyendo a determinar si hubo o no hecho de la víctima, de terceros o de la naturaleza en el daño producido, y ayudando de este modo a determinar cuál es el monto a pagar por la Compañía. (Sentencia del Tribunal Constitucional rol 1295-08, 2009: considerando nonagésimo octavo)

\section{¿Llega a ser una privación?}

La limitación no puede llegar al punto de constituir una privación. Tal como ya hemos señalado, limitar y expropiar son cuestiones distintas, y solo con la segunda nace un derecho a indemnización.

La diferencia entre limitar y expropiar suele marcar el clivaje argumentativo. Así, ya en 1996 el Tribunal Constitucional decía:

No hay privación total del uso y goce pero sí una limitación que hace ilusorio estos atributos del dominio y que es indudable que en la especie causa daño y que este debe ser indemnizado [...] si bien no priva totalmente de los atributos de uso y goce de la propiedad, en el hecho hace ilusorio estos atributos. (Sentencia del Tribunal Constitucional rol 245-96, 1996: considerando trigésimo cuarto)

En el mismo sentido, señalaba en 2001:

No solo se produce privación del dominio cuando se le despoja a su dueño totalmente de él o de uno de sus atributos o facultades esenciales, sino, también, cuando ello se hace parcialmente o mediante el empleo de regulaciones que le impidan libre- 
mente ejercer su derecho o uno de sus atributos mencionados. (Sentencia del Tribunal Constitucional rol 334-01, 2001: considerando décimo noveno)

A su vez, el modo en que la doctrina norteamericana ha desafiado el deslinde entre limitar y expropiar con la doctrina de la «expropiación regulatoria», recogido en alguna ocasión por la jurisprudencia constitucional chilena, sugiere que una limitación cuando llega a ser demasiado intensa desnaturaliza el dominio del sujeto:

No solo se produce privación del dominio cuando se le despoja a su dueño totalmente de él o de uno de sus atributos o facultades esenciales, sino, también, cuando ello se hace parcialmente o mediante el empleo de regulaciones que le impidan libremente ejercer su derecho o uno de sus atributos mencionados, como ocurre en este caso. (Sentencia del Tribunal Constitucional rol 334-01, 2001: considerando décimo noveno $)^{7}$

Pero esta doctrina ha sido ya matizada y superada por el mismo Tribunal Constitucional. En el último tiempo, la magistratura se ha preocupado de acotar este criterio solo a las limitaciones que producen, en efecto, una afectación muy intensa del dominio, y así, no admite indemnización por cualquier limitación del derecho de propiedad, porque eso sería despojar de toda operatividad real a la función social de la propiedad. Así, ha señalado:

En el requerimiento solo se afirma que la declaración de Zona Típica constituye 'una limitación exorbitada' (fojas 9) y que 'se impone al titular del derecho de propiedad de un bien declarado Zona Típica una carga que tiene la naturaleza de privar de manera esencial al propietario de los atributos de uso y goce inherentes o que, al menos, los limita muy severamente (en su esencia)' (fojas 13), sin que se demuestre el real grado de afectación que importaría el desarrollo del proyecto inmobiliario. (Sentencia del Tribunal Constitucional rol 2299-12, 2014, considerando vigésimo cuarto)

\section{¿Afecta la seguridad jurídica?}

No obstante lo anterior, recientemente en un fallo de mayo de 2019, el Tribunal Constitucional parece haberse apartado de su jurisprudencia ya asentada. Así, ha entendido que uno de los objetivos de la garantía constitucional del numeral $24 .^{\circ}$ del artículo 19 de la Constitución es «otorga[r] al propietario la suficiente seguridad jurídica para su pleno ejercicio» (Sentencia del Tribunal Constitucional rol 5172-18, 2019: considerando vigésimo tercero), de modo que restringe considerablemente el campo de acción de la regulación, pues limita la posibilidad de cambio regulatorio. En este sentido, afirma:

Las limitaciones al dominio deben ser armónicas con la seguridad jurídica que tiene que contener el ordenamiento jurídico en términos que no afecten el contenido esencial de la propiedad, estableciéndose normas jurídicas que contengan condiciones

7. En el mismo sentido, (Sentencia del Tribunal Constitucional 505-06, 2007). 
estables que conlleven a situaciones de certeza. (Sentencia del Tribunal Constitucional rol 5172-18, 2019: considerando vigésimo sexto)

La comprensión anterior implica una restricción importante de la afectación de la propiedad que permite su función social, pues siguiendo el argumento del Tribunal Constitucional hasta sus últimas consecuencias, en nombre de la seguridad incluso podrían llegarse a proteger meras expectativas, en la medida en que se funden en una determinada regulación que se esperaba no fuera modificada.

\section{Conclusiones}

Al final de esta recopilación y sistematización, podemos trazar algunas conclusiones.

La mayoría de las Constituciones en el derecho comparado contemplan la noción de función social como límite al derecho de propiedad, y así la contemplaba también la Constitución chilena de 1925 tras las reformas de la década del sesenta. Por lo tanto, la Constitución de 1980 no es novedosa a este respecto, ni en relación con los textos constitucionales previos ni a otras cartas fundamentales.

La función social es un concepto típicamente constitucional, que convoca a la legislación a su desarrollo más lato. En nuestro ordenamiento jurídico, la ley perfila el régimen de la propiedad precisamente a través de la concreción de las limitaciones que se derivan de su función social, y la jurisprudencia constitucional ha complementado esta labor por la vía de definir el contenido de la función social de la propiedad y delimitar su ámbito de aplicación.

Así, el Tribunal Constitucional ha elaborado un concepto de función social de la propiedad, ha definido un deslinde entre expropiación y limitación, ha acogido y luego superado la doctrina de la expropiación regulatoria anglosajona; en definitiva, ha asumido la tarea de interpretar la norma constitucional. Así, ha pasado por etapas, desde una inicial afirmación de la intangibilidad de los contratos, a sostener finalmente que la función social se aplica a todo tipo de propiedad. Se ha referido además a las limitaciones en la Constitución y a las limitaciones que derivan de la función social en particular, y ha señalado que es la ley la encargada de establecer estas limitaciones. Por último, ha construido una batería de criterios de resolución para determinar cuándo una limitación es lícita y cuándo no.

\section{Referencias}

Aldunate, Eduardo (2006). «Limitación y expropiación: Scilla y Caribdis de la dogmática constitucional de la propiedad». Revista Chilena de Derecho, 33 (2): 285-303. CEA, José Luis (2012). Derecho constitucional chileno. Tomo 2. Santiago: Ediciones UC. Claro Solar, Luis (1945). Explicaciones de derecho civil chileno y comparado. Tomo 1. Santiago: Jurídica.

Comisión de Estudios de la Nueva Constitución (1978). Memorándum de 16 de 
agosto de 1978, dirigido por la Comisión de Estudios de la Nueva Constitución al Presidente de la República. Santiago: s.e.

Nogueira Alcalá, Humberto (2010). Derechos fundamentales y garantías constitucionales. Tomo 4. Santiago: Librotecnia.

Rodríguez, Pedro (1972). «La propiedad privada». Revista de Derecho y Jurisprudencia, 69: 111-142.

\section{Sobre las autoras}

Ximena Peralta Fierro es Licenciada en Ciencias Jurídicas y Sociales de la Facultad de Derecho de la Universidad de Chile. Su correo electrónico es ximenaperalta93@ gmail.com. (iD https://orcid.org/0000-0002-4032-1090.

Isabel Yáñez Morales es Licenciada en Ciencias Jurídicas y Sociales de la Facultad de Derecho de la Universidad de Chile. Su correo electrónico es isabel.yanez@ ug.uchile.cl. (iD) https://orcid.org/0000-0003-1982-9823. 